\title{
Alberto Mussa e Enrique Vila-Matas: OS LIMITES DO ROMANCE, O ENSAIO E A CRÍTICA LITERÁRIA
}

\section{Rafael Gutiérrez}

De maneira destacada ao longo das últimas duas décadas, embora a estratégia tenha diversos antecedentes, vem aparecendo no panorama literário um tipo de texto narrativo que leva críticos e leitores a questionarem sobre a condição e o estatuto ficcional dele. Livros que não se deixam circunscrever com facilidade em definições fechadas de gênero, forçando a criação de categorias alternativas como romance-ensaio, autoficção, formas híbridas, entre outras. Livros, enfim, que parecem querer sair de seus próprios limites, tencionando as margens da literatura.

Este ensaio procura se aproximar desse tipo de obra da literatura contemporânea, especificamente textos do brasileiro Alberto Mussa e do espanhol Enrique Vila-Matas. Os livros desses autores misturam em sua construção diversos registros discursivos, usando recursos da prosa narrativa, do ensaio, da crítica literária e da autobiografia. Trata-se de textos que se situam na fronteira entre o ficcional e o documental, tencionando permanentemente esses limites.

\section{ALBERTO MUSSA E O ROMANCE-ENSAIO}

Alberto Mussa nasceu no Rio de Janeiro em 1961. Estudou matemática e literatura. Escritor e tradutor realizou a tradução para o português dos Poemas Suspensos, poesia árabe pré-islâmica, publicada em 2006. A maior parte de sua obra se caracteriza pela mistura do registro ensaístico 
e ficcional e pelo uso de diversas mitologias e tradições literárias na construção de seus textos. Em $O$ enigma de Qaf, de 2004, a poesia árabe e a própria linguagem aparecem como eixo central de uma narrativa construída como uma pesquisa que explora a história da literatura, cultura e mitologia árabes. Em Meu destino é ser onça (2008), a partir de fontes documentais Mussa recria o que teria sido o texto original da narrativa mitológica da tribo tamoios, os tupinambás do Rio de Janeiro.

Em O movimento pendular, publicado em 2006, Mussa (2006, p.11) se vale do tema do adultério para construir um livro que percorre diversas tradições literárias e mitologias com o objetivo de definir uma teoria ou "história tipológica do triângulo amoroso". Vou me deter de maneira central neste último texto para discutir suas estratégias compositivas e as implicações teóricas em relação ao estatuto problemático dessas formas mistas contemporâneas.

Igualmente a $O$ enigma de Qaf, $O$ movimento pendular (de agora em diante, OMP) possui uma estrutura muito bem definida e articulada, embora neste caso se perceba um jogo mais direto com a linguagem do discurso matemático. OMP se organiza em seis sequências, uma Advertência preliminar e um Apêndice. Cada uma das sequências da narrativa corresponde à demonstração de um determinado postulado relacionado com a ideia central do triângulo amoroso. Na primeira sequência, por exemplo, seria demonstrado o postulado: "Todo triângulo é transformação de um mesmo triângulo original e único” (MUSSA, 2006, p. 17). Na segunda sequência, o seguinte postulado: "Personagens semelhantes, em circunstâncias semelhantes, formam os mesmos triângulos" (p. 51). E assim por diante.

O livro começa pela explicação do triângulo amoroso composto pelos vértices alfa, beta e gama. Cada vértice representando um dos personagens do triângulo: alfa, a vítima da traição; beta, esposo(a) ou namorado(a) da vítima; e gama, o sedutor(a), o elemento perturbador. A partir dessa tipologia básica, o livro se constrói apresentando diversas histórias de adultério que representam algumas possibilidades de desenvolvimento do triângulo, dependendo das ações tomadas pelos personagens; por exemplo, o caso em que alfa se vinga de beta e gama, assassinando-os. O autor passa a narrar e recriar histórias das mitologias egípcia, grega e indígena, e de obras literárias, para exemplificar essas diversas possibilidades.

Para dotar o livro com um ar ainda mais científico, no Apêndice é apresentada uma lista resumida da tipologia dos triângulos amorosos, 
remetendo a algumas das histórias incluídas no livro. Por exemplo, o triângulo Patético, no qual alfa (a vítima da traição) renuncia à relação com beta (esposa), impondo um dano a si mesmo; no livro seria o caso de Shi Huang Di, que toma uma poção venenosa depois de descobrir o adultério entre sua esposa, cujo nome não é informado, e Li Si, seu rival.

Um aspecto que salta à vista desde a Advertência, no início do livro, é precisamente o jogo de ambiguidade quanto a seu caráter ficcional. $\mathrm{O}$ próprio autor afirma que se trata de uma coleção de histórias de adultério organizadas de forma sistemática e que propõem uma teoria do triângulo amoroso. Dessa forma, é criada a ilusão de que nos encontramos no território do ensaio e do tratado científico. Inclusive o livro inclui em diversos momentos tabelas, gráficos e equações matemáticas, como estas da página 128, reproduzidas a seguir: mesmos elementos, três percepções diferentes.

Considerada a percepção de cada personagem, temos a matriz de traços distintivos:

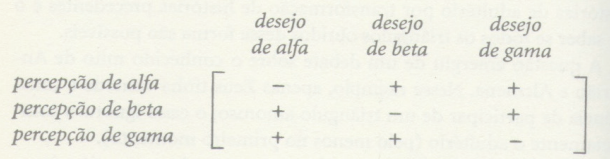

Posso definir, assim, três conjuntos a partir das linhas da matriz, respectivamente constituídos pelos elementos tomados às colunas. Designando por $\left(\alpha^{-}\right)$ao sinal negativo na coluna "desejo de alfa", $\left(\beta^{+}\right)$ao positivo na coluna "desejo de beta", e assim sucessivamente, as linhas da matriz tomam a seguinte forma gráfica:
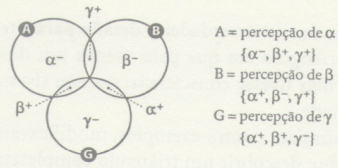

Um observador teoricamente presente à cena no templo da Serpente Emplumada, que tivesse cometido o mesmo erro na interpretação dos olhares, teria percebido um quarto conjunto, em que todas as personagens estão sexualmente interessadas no adultério. É este o conjunto formado pela reunião das interseções, indicado pelas hachuras abaixo:

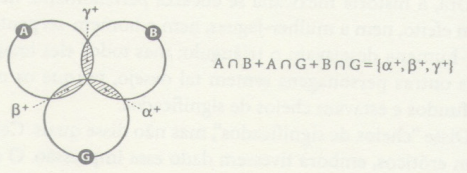

128

Figura 1. Gráficos e equações matemáticas do livro $O$ movimento pendular.

Fonte: Mussa (2006, p. 128). 
O próprio Mussa ([s.d.], [s.p]) afirma que: "Meu livro é, de certa forma, um subgênero da chamada ficção-científica; ou o inverso dela, uma espécie de ciência-ficcional”. Uma mescla de ficção, história, conto, ensaio e até símbolos gráficos tirados do campo da matemática. Sem dúvida os procedimentos de Mussa se localizam na linha de tradição borgeana, experimentando com os limites entre ensaio e ficção, misturando histórias reais e fictícias, falando de autores inventados como se fossem reais ou tergiversando sobre fatos e histórias verdadeiras.

Mas, onde se situa nesse caso o limite entre ensaio e narrativa de ficção? Se pensarmos na mistura de teoria e exemplos narrativos, alguns deles histórias reais, outros, fictícias, poderemos ver o livro como um exemplo contemporâneo dos tratados antigos. No seu contexto, esses livros não eram considerados ficcionais, por mais que incluíssem histórias inventadas. No nosso atual contexto de recepção, aparentemente o livro de Mussa é classificado na categoria de ficção. Assim pelo menos acontece com sua classificação na ficha catalográfica e nas resenhas realizadas sobre o livro, ${ }^{1}$ as quais destacam esse caráter híbrido que estamos mencionando.

Similar ao que poderia acontecer com um livro como La literatura nazi en América, de Roberto Bolaño, é possível que o livro de Mussa leve alguns leitores a identificá-lo como ensaio ou tratado ensaio ou tratado, embora uma leitura mais minuciosa descarte essa possibilidade. Ainda assim uma dúvida continua: por que insistir em que se trata de uma ficção e, nesse sentido, falar do texto como um romance? Por que não o tratar efetivamente como uma possibilidade do ensaio?

Precisamente porque o ensaio parece estar em uma posição de desconforto no campo literário, a meio caminho entre o mundo da teoria e dos conceitos e o mundo da expressão da subjetividade e da escrita criativa. Esse fator incômodo faz parte justamente de sua própria essência e razão de ser. $\mathrm{O}$ ensaio é geralmente caracterizado pela dificuldade para estabelecer seus limites precisos como gênero, pela heterogeneidade de materiais, procedimentos e métodos que utiliza, e por sua pretensão exatamente de não ser sistemático. Tudo isso tem a ver com sua posição ambígua e inclassificável. Nesse sentido é possível ver na essência do ensaio formas e mecanismos que caracterizam a própria literatura. como a ambiguidade, a experimentação, a procura constante, a abertura para outros registros.

\footnotetext{
${ }^{1}$ Ver, por exemplo, a resenha de Luiz Paulo Faccioli (2007), publicada no jornal Rascunho.
} 
Se o ensaio pertence ao mundo da poesia (entendida como escrita criativa) ou ao mundo da ciência e da filosofia, essa é uma questão debatida longamente pelos teóricos do ensaio. Adorno (2003) contrapõe-se à visão de Lukács (1970) - ambos textos já clássicos sobre o tema -, e coloca o ensaio mais perto da ciência e da teoria do que das formas artísticas. Para Adorno o ensaio se aproxima de uma autonomia estética como a arte, mas se diferencia pelos conceitos e por sua pretensão de verdade.

Entretanto, a essência do ensaio está em seu processo, não em sua conclusão. É a própria escrita do ensaio que o faz ainda interessante, mesmo quando suas verdades são ultrapassadas e refutadas (como acontece, por exemplo, com um texto como Anatomia da melancolia, de Robert Burton). Esse ponto de vista aproxima muito mais o ensaio dos demais gêneros literários do que do discurso da ciência e da filosofia sem, no entanto, desligar-se completamente dessa procura de verdade, como vimos antes.

Tem ou não o texto de Mussa essa pretensão de verdade que seria um fator decisivo para separar ficção e não ficção? Escutemos por um momento a própria opinião do autor:

\footnotetext{
Pensei, então, em fazer uma ficção em que o narrador - um teórico - proporia outra tese: a de que o conceito de adultério foi anterior ao de incesto, sendo o adultério, e não o incesto, essa instituição fundamental dos Homo sapiens [...] O Movimento Pendular pode ser considerado romance porque a voz do narrador - teórico que estuda as histórias de triângulos amorosos - dá unidade ao todo. O romance é a própria teoria e a classificação desenvolvidas pelo narrador. As histórias que ele conta não estão soltas porque formam uma cadeia de raciocínio que demonstra a teoria. Elas são na verdade as personagens do romance (MUSSA, [s.d.], [s.p.]).
}

Para Mussa o livro seria uma ficção, especificamente um romance por conta da existência de um narrador que dá unidade ao todo, embora o que esteja no fundo do texto seja a elaboração de uma teoria, com suas propostas de conceitos, postulados e exemplos concretos para demonstrálos.

Pareceria que a diferença entre ensaio e romance, nesse caso, seria estabelecida pela figura de um narrador, no segundo, que substituiria a voz direta do autor, presente no ensaio. Lembremos que uma das características destacadas pelos teóricos do ensaio está relacionada com a proximidade entre o tema e o sujeito que enuncia o discurso. Nesse sentido o ensaio se apresenta como um tipo de escritura que é a mais próxima possível do sujeito. Mussa fala de um narrador como se fosse 
um personagem inventado por ele, no entanto, em nenhum momento é explicitado que quem narra seja um personagem distinto daquele que assina, como autor do livro, na capa e primeira página: Alberto Mussa.

Efetivamente, tirando a classificação na ficha catalográfica e quiçá algumas referências intertextuais com a obra de Borges, não há nenhuma marca de distinção na própria matéria textual desse livro de Mussa que nos permita estabelecer de maneira evidente seu pertencimento ao registro ficcional ou ao registro não ficcional. No caso desse autor, a marca de ficcionalidade estaria dada de maneira mais clara a partir do exterior, pelo próprio discurso do autor e pela recepção crítica do texto.

Durante todo o percurso do livro, então, transitamos por um discurso que simula e recria o discurso do ensaio e o do tratado, experimentando também com a pretensão de verdade desses gêneros. Nesse sentido, poderíamos afirmar que o caso de OMP, assim como no de outros livros similares, situa-se no tradicional "como se" da ficção. Como afirma J. R. Searle (1994, p. 65 ss.), a partir do ponto de vista da atitude linguística, o escritor de ficção não realiza um ato ilocutório assertivo "sério", mas se limita a fingir fazê-lo. ${ }^{2}$ Mussa não escreve um tratado científico "sério" sobre o adultério, mas se limita a fingir que o faz, usando muitas das estratégias discursivas, simbólicas e narrativas desse tipo de discurso.

Como no caso da autoficção, por exemplo, vemos que o que gera esse efeito desestabilizador - mais ainda do que o que acontece nos romances tradicionais (com desenvolvimento de um enredo, trama, argumento, personagens) -, é essa proximidade com gêneros do discurso que possuem uma pretensão de verdade, como o ensaio, o tratado e a autobiografia. Desse modo, essas formas mistas contemporâneas retomam uma velha estratégia de simulação do romance com a qual pretendem dotar seus textos de um tom aparentemente documental.

De fato, essas estratégias discursivas que ostentam formas híbridas atuais não são novas, muito pelo contrário, parecem retomar questões atreladas ao próprio surgimento do gênero romance, tal como estudado por autores como Ian Watt (2010) ou Catherine Gallagher (2009), no sentido de que precisamente o romance surge apropriando-se de outros

\footnotetext{
${ }^{2}$ Karlheinz Stierle (2006, p. 88) faz uma crítica à discussão analítica do estatuto lógico da ficção; segundo ela, a esse tipo de abordagem "[...] escapa-lhe que a verdade da ficção é a sua forma e não o fato de serem sérios ou 'não sérios' seus enunciados. Não se trata na ficção do valor de verdade das frases ficcionais, mas sim de figuras apelativas complexas e de atualizar o apelo que estas produzem".
} 
gêneros discursivos de não ficção (a matriz news-novel, por exemplo, as crônicas escandalosas, as sátiras políticas).

Chama a atenção, então, que se lhes outorgue tal nível de destaque nos contextos de recepção atuais, às vezes, inclusive, sobredimensionando o efetivocaráter híbrido, ou misto, dessas formas narrativas contemporâneas, como afirma Antônio Marcos Pereira (2011), ao analisar, por exemplo, o caso de um livro como Anéis de Saturno, de W. G. Sebald. Pereira questiona o fato de que a recepção geral do livro exagera na valorização de seu caráter aparentemente híbrido ou de indeterminação genérica, ao invés de considerá-lo como uma tentativa original do discurso ensaístico.

Quiçá o que está por trás dessa atitude seja a necessidade de identificar novas possibilidades de renovação de um gênero (o romance) que, para muitos, pode ter chegado (ou chegou faz tempo) a certo esgotamento formal. Em relação às formas híbridas, tentativas como as estudadas aqui parecem se situar nesse contexto como alternativas possíveis à estrutura mais institucionalizada do romance - considerando-se como institucionalizadas inclusive formas mais experimentais, jogos com os tempos narrativos, não linearidade, falta de uma história unificadora, alto grau de autoconsciência narrativa etc.

Certa negação ou impossibilidade de voltar à velha ideia de "contar uma história” parece estar também por trás desse tipo de estratégia, algo que o próprio Mussa menciona em relação à suas práticas de escrita ${ }^{3} \mathrm{e}$ que aparece com frequência também no discurso e nas obras do espanhol Enrique Vila-Matas. ${ }^{4}$

\section{ENRIQUE VILA-MATAS E A CRÍTICA LITERÁRIA COMO FICÇÃO}

O espanhol Enrique Vila-Matas (Barcelona, 1948) é comumente associado com uma tendência hiperliterária da literatura contemporânea. Em grande parte da obra de Vila-Matas, o mundo da literatura se torna

\footnotetext{
${ }^{3} \mathrm{Na}$ entrevista citada anteriormente (MUSSA, [s.d.], [s.p]), o escritor afirma: "Não sei escrever romances, no sentido estrito do termo [...] Minha vocação é de contista, mas luto contra ela. Não me agrada o modelo clássico dos livros de contos".

4 Vila-Matas (2001, p. 13) afirma, em entrevista para a revista Qué Pasa, que com "El viaje vertical" [A viagem tropical] dizia adeus ao romance e que a partir desse momento queria fazer "un libro que mezcle géneros, una caja abierta donde cabe todo" [um livro que misture gêneros, uma caixa aberta na qual cabe tudo].
} 
o tema central. A reflexão crítica sobre o próprio processo de criação literária, assim como questões teóricas relacionadas com a literatura de um modo geral aparecem, seja através de seus personagens ficcionais (que costumam ser também escritores, poetas ou críticos) ou de maneira direta, em textos que não desenham limites evidentes entre a crítica, a história literária, a ficção e a autobiografia.

No entanto, a proposta literária de Vila-Matas se afasta um pouco do gesto metaliterário, entendido somente como reflexão e explicitação do próprio processo de escrita da obra, para se aproximar de um tipo de registro reflexivo sobre o campo da literatura em geral - as vidas de escritores, críticos e leitores - e as diversas tensões que o atravessam, bem como do campo teórico da literatura.

Assim como Mussa se aproxima do registro do ensaio e do tratado científico, Vila-Matas se apropria ficcionalmente de registros típicos da história, da crítica e da teoria da literatura. Talvez o caso do segundo seja um dos mais evidentes entre as propostas contemporâneas de aproveitamento ficcional da crítica e da história literária. Uma estratégia que tem antecedentes importantes: Borges, novamente como uma influência iniludível; mas vale também mencionar livros como Vácuo perfeito (1971), de Stanislam Lem, ou, no contexto brasileiro, o caso de $A$ rainha dos cárceres da Grécia (1976), de Osman Lins, assim como propostas como O loro de Flaubert (1984), de Julian Barnes, para mencionar só alguns casos significativos. Todas propostas que se afastam de diversos modos da estrutura convencional do romance como desenvolvimento de um enredo e de peripécias dos personagens, e que incorporam registros típicos da história, da crítica e da teoria literária.

No entanto é necessário aclarar que a obra de Vila-Matas é ampla e variada, e que nem todos os seus livros obedecem às mesmas estratégias narrativas. Os de contos, assim como alguns romances, embora mantenham sempre as referências ao mundo da literatura, afastamse das estratégias híbridas que estou analisando. Outros de seus livros, especialmente Historia abreviada de la literatura portátil (1985), Bartleby y compañía (2000), 5 El mal de Montano (2002) ou Doctor Pasavento (2006), situam-se nessa fronteira entre romance, teoria e história literária. Precisamente o editor da editora Anagrama, Jorge Herralde, chamou ao

${ }^{5}$ De agora em diante, Bartleby... 
conjunto de textos composto por Bartleby..., El mal de Montano e Doctor Pasavento como "La catedral metaliteraria".

À maneira de exemplo, vamos nos centrar em Bartleby... para analisar algumas de suas características e estratégias relacionadas com nosso tema de interesse. Publicado no ano 2000, o livro se define como um "diário" ou "notas a pé de página", que comentam um suposto texto invisível. O narrador (já nos deteremos um pouco nele) se dedica a rastrear "bartlebys", escritores que por alguma razão deixaram de escrever ou ficaram bloqueados nos seus processos criativos, e que recebem seu nome do personagem do conto de Herman Melville, Bartleby, o escrivão. O narrador do livro de Vila-Matas (2000, p. 12) afirma que:

Hace tiempo ya que rastreo el amplio espectro del síndrome de Bartleby en la literatura, hace tiempo que estudio la enfermedad, el mal endémico de las letras contemporáneas, la pulsión negativa o la atracción por la nada que hace que ciertos creadores, aun teniendo una conciencia literaria muy exigente (o quizás precisamente por eso), no lleguen a escribir nunca; o bien escriban uno o dos libros y luego renuncien a la escritura $[\ldots]{ }^{6}$

A estrutura narrativa de Bartleby... passa então a se organizar na forma de entradas numeradas que correspondem à descrição e análise de diversos casos da síndrome de Bartleby. Entre os autores analisados no livro, aparecem Robert Walser, Juan Rulfo, Rimbaud, o escritor espanhol Felipe Alfau e o próprio Herman Melville. Ao lado da narração das experiências desses escritores e dos motivos que os teriam levado a deixar de escrever, o texto está repleto de citações de textos de outros escritores, críticos e ensaístas, assim como de reflexões sobre o tema analisado. Como no caso de Mussa (e de muitos outros autores contemporâneos), no texto se misturam de maneira indiscriminada referências a pessoas reais e referências inventadas. Ao lado de citações de Victor Hugo, Maurice Blanchot ou do escritor e historiador francês Marcel Bénabou, aparecem referências fictícias como, por exemplo, a menção ao livro Instituto Pierre Menard, do suposto escritor Roberto Moretti.

Embora a narrativa sem dúvida esteja mais próxima do gesto ensaístico e de certa história da literatura, ela está marcada pela

\footnotetext{
6 "Faz tempo já que rastreio o amplo espectro da síndrome de Bartleby na literatura, faz tempo que estudo a doença, o mal endêmico das letras contemporâneas, a pulsão negativa ou a atração pelo nada, que faz com que certos criadores, embora tendo uma consciência literária muito exigente (ou quiçá justamente por isso), não cheguem a escrever nunca; ou escrevam um ou dois livros e depois renunciem à escritura."
} 
experiência do narrador que descreve o processo de escritura do livro e que em alguns momentos toma emprestados rasgos do próprio Vila-Matas, algo que se repete em muitos de seus livros experimentando com o registro autobiográfico. Mas, no caso do escritor catalão, fica evidente uma estratégia de autofabulação, mais do que um jogo com a sinceridade autobiográfica. Vila-Matas distorce de forma evidente os rasgos e fatos relacionados com sua biografia, por mais que deixe aqui e ali alguns detalhes verificáveis. Em Bartleby..., por exemplo, existem algumas referências a sua figura de escritor e seus textos anteriores, mas o personagem narrador é descrito de maneira patética como portador de uma corcunda, empregado de escritório não muito feliz e com pouca sorte com as mulheres (rasgos irônicos com que o próprio Vila-Matas costuma disfarçar as diversas figurações e autofigurações do escritor).

Bartleby..., assim como outros de seus livros, já citados anteriormente (Historia abreviada..., El mal de Montano, Doctor Pasavento), utilizam a própria figura do escritor, seus processos criativos, suas dificuldades, suas dúvidas, suas reflexões sobre a literatura como matéria primordial da elaboração narrativa. Trata-se de certo tipo de romance de artista, na medida em que toma como centro de sua temática a vida do escritor, mas que envereda pelos caminhos do ensaio e do registro da história literária para construir textos que se situam nessas difusas fronteiras genéricas que estamos discutindo.

Talvez Bartleby... seja um dos textos mais representativos dessa tentativa híbrida, dada a predominância do gesto ensaístico sobre o narrativo, contrário ao que pode acontecer nos outros textos da "catedral metaliterária”. Tanto em El mal de Montano como em Doctor Pasavento, acompanhamos mais claramente o percurso do narrador e de alguns personagens centrais; entretanto, em Bartleby... predomina o tom reflexivo e, com algumas poucas exceções, os personagens da história (escritores) se apresentam como casos de estudo de uma tese teórica: a impossibilidade de narrar, que estaria na base da literatura moderna.

Por outro lado, como já destacamos anteriormente, não é algo novo que um tipo de reflexão crítica e teórica apareça no interior de textos que se apresentam como ficcionais (romances e relatos). Pelo contrário, esse é um fenômeno que pode ser rastreado há bastante tempo na tradição literária ocidental. Uma tendência autorreflexiva que vai se afiançando com o tempo, até chegar a textos (poemas, contos e romances) que se voltam totalmente para a própria literatura e o ato da escrita, estratégia 
que se torna predominante mais ou menos a partir dos anos 6o do século XX, e permanece até o presente em ficções que usam a literatura e os próprios escritores como temas e personagens, ou que misturam permanentemente diversos registros discursivos, experimentando com as fronteiras dos gêneros tradicionais e os limites entre o real e o ficcional.

O próprio discurso crítico dos estudos literários (pelo menos uma parte importante dele) participa também dessas transformações, abandonando as pretensões de objetividade e reconhecendo plenamente o papel da subjetividade do pesquisador ou crítico da literatura. Estes tendem a assumir e aproveitar de maneira consciente a qualidade de discurso, de escritura e de criação da própria elaboração crítica e teórica.

Vão nesse sentido também a crítica e a teoria, as quais têm se aproximado de certas estratégias ficcionais e ensaísticas que, sem abandonar sua função de reflexão teórica sobre o objeto literário (etambém sobre outros objetos culturais), incorporam em seu processo escritural estratégias antes reservadas ao campo mais amplo do literário, como, por exemplo, extratos de diários, incursão da própria subjetividade e conflitos íntimos do crítico, reconhecimento das relações entre o pesquisador e seu objeto de estudo, técnicas autobiográficas, uso de descrições e técnicas narrativas em seus escritos etc.

Nesse aspecto, o exemplo de crítica e reflexão teórica realizadas pelos mesmos escritores podem servir, em alguns casos, como antecedente das transformações do campo crítico, seja ele acadêmico ou institucional. Não é casualidade que Borges tenha sido uma referência central para a nova crítica que aparecia na França, vinculada a nomes como os de Maurice Blanchot e Roland Barthes; e não é casualidade que esses autores apareçam frequentemente nas referências dos textos crítico-ficcionais de Vila-Matas.

Embora a maioria dos escritores pratique em algum momento de sua carreira algum tipo de gênero crítico ou teórico (ensaios, notas, resenhas, anotações), é evidente que alguns se destacam por fazer da crítica uma tarefa fundamental, no mesmo nível que o de sua própria prática como narradores ou poetas. É este o caso típico do escritor-crítico ou do poetacrítico. 7 As figuras paradigmáticas frequentemente citadas para ilustrar esse caso na literatura ocidental são as de Ezra Pound e T.S. Eliot. No

7 Em um movimento de sentido contrário, embora relacionado, Tzvetan Todorov (1984) identificava alguns casos exemplares de críticos-escritores (Sartre, Blanchot e Barthes), nos quais a crítica se torna ela mesma literatura. 
contexto latino-americano poderíamos mencionar Borges - cuja obra caracteriza-se precisamente por realizar uma mistura original entre os gêneros críticos e os ficcionais -, Octavio Paz, Haroldo de Campos ou Severo Sarduy como exemplos destacados da figura do poeta/escritor-crítico.

No entanto o que diferencia casos como os de Vila-Matas ou Bolaño, de figuras como Octavio Paz ou Ezra Pound, é, nos primeiros, a simultaneidade dos gestos críticos e ficcionais em textos que são indiferentes ao estabelecimento de limites precisos ou que se satisfazem com essa ambiguidade genérica, seguindo o caminho percorrido por Borges. Embora Vila-Matas tenha publicado textos caracterizados propriamente como ensaio em Para acabar con los números redondos (1997) ou El viento ligero en Parma (2004), parece haver uma continuidade de registro que, embora muito mais fragmentário no caso dos livros de ensaios e reflexões, mantém o mesmo caráter indeterminado que perpassa seus livros ficcionais.

Esse tipo de voz singular que adquire o narrador vilamatiano se vincula com propostas narrativas como as de Mussa, Bolaño ou os últimos textos do mexicano Sergio Pitol (especialmente a chamada Trilogía de la memoria). Refiro-me a certa voz narrativa de tipo autobiográfico, que se desenvolve a partir de outras leituras e referências literárias, formando textos nos quais a experiência de vida aparece sempre atrelada à literatura e à experiência da leitura.

Trata-se de uma voz particular (extensiva a muitos narradores e narradoras contemporâneos) que ao mesmo tempo é uma voz pessoal, mas que não cai necessariamente no registro biográfico - como seria o caso em geral da chamada autoficção -, mas que deriva para uma linha mais reflexiva e ensaística. José María Pozuelo (2010, p. 30) a define como "voz reflexiva", comumente associada ao registro do ensaio:

Tal voz reflexiva realiza esa figuración personal, pero, eso sí, a diferencia de la del ensayo, resulta enajenada de ellos [os autores] en cuanto responsabilidad testimonial, y se propone como acto de lenguaje fictício vehiculado por sus narradores. ${ }^{8}$

\footnotetext{
8 “Tal voz reflexiva realiza essa figuração pessoal, mas, a diferença do ensaio resulta alienada deles [os autores], enquanto responsabilidade testemunhal, e se propõe como ato de linguagem fictícia veiculado pelos seus narradores."
} 
Essa voz figurada nos textos de Vila-Matas aparece como um lugar no qual se comunicam de forma solidária um eu pensante e um eu narrativo. É precisamente essa deriva narrativa, unida ao fato de misturar eventos e personagens reais e imaginários, fugindo desse modo da pretensão de verdade, o que não permite que livros como Bartleby... entrem comodamente na categoria de ensaio da qual se aproximam muito mais, a nosso modo de ver, do que do romance tradicional.

\section{EPÍLOGO}

Embora sem desconhecer a tentativa desses autores de explorar sendas literárias alternativas, identifico essas formas híbridas como herdeiras de certa tradição autorreflexiva e metaliterária por um lado e, por outro, como formas que parecem recuperar (intencionalmente ou não) mecanismos que surgem no próprio cerne do romance e do conceito de ficção, tal como ainda hoje o compreendemos. Os mecanismos e as estratégias dessas formas híbridas, unidos aos efeitos de indeterminação genérica que produzem, levam a destacá-las como formas narrativas que explicitam e problematizam precisamente o próprio estatuto da ficção e do literário.

Em linhas gerais, poderíamos dizer que essas formas destacam o próprio caráter híbrido que seria constitutivo do discurso ficcional. Ao se colocar explicitamente nessas zonas de fronteira, parecem apontar para a desestabilização de certas convenções ou pactos institucionalizados entre autores e leitores. Paradoxalmente, ao tentar trair esses pactos realmente estariam voltando a evidenciar o caráter ambíguo e indeterminado constitutivo do estatuto ficcional.

Por outro lado, e a partir de um ponto de vista formal, acredito que a aposta nesta mistura de gêneros e registros discursivos pode também obedecer a uma procura por alternativas narrativas aos modos de certo tipo de romance que, para esses escritores, aparece como esgotado ou literariamente pouco atrativo. Desse modo, recursos formais como a elaboração de livros que utilizam o registro enciclopédico, o biográfico, dos tratados científicos ou da crítica e a história da literatura, aparecem como vias alternativas de escritura ficcional que fogem à tradicional construção de um enredo e caracterização de personagens dramáticos. Técnicas, obviamente, que não são novas, nem originais, mais que parecem adquirir uma maior relevância como alternativa frente à estandardização 
mercadológica do romance (romance histórico, best-seller), mas também de uma boa parte do romance sério ou de alta literatura.

Nesse sentido é interessante destacar a frequência com que tem aparecido esse tipo de voz, entre reflexiva e narrativa, que Pozuelo identificava para o caso de Vila-Matas, mas que pode ser estendida para muitos outros escritores e escritoras contemporâneos. Se de um lado esse registro poderia se incorporar a certa volta do autor, como tem sido definida recentemente, embora não caia necessariamente no registro do autobiográfico tradicional, ao mesmo tempo continua a senda metaliterária e autorreflexiva do romance moderno.

\section{REFERÊNCIAS}

ADORNO, Theodor. Notas de literatura I. Trad. Jorge M. B. de Almeida. São Paulo: Duas Cidades / Editora 34, 2003, pp. 15-46.

BOLAÑO, Roberto. La literatura nazi en América. Barcelona: Seix Barral, 1996.

FACCIOLI, Luiz Paulo. O pêndulo da traição. Rascunho, n. 81, jan. 2007, p. 22.

GALLAGHER, Catherine. Fiç̧ão. In: MORETTI, Franco (org.). A cultura do romance. Trad. Denise Bottman. São Paulo: Cosac e Naify, 2009.

LUKÁCS, Georg. El alma y las formas. México: Grijalbo, 1970, pp. 15-42.

MUSSA, Alberto. O movimento pendular. Rio de Janeiro: Record, 2006.

MUSSA, Alberto. Entrevista sobre O movimento pendular. S. d. Site do Grupo Editorial Record. Disponível em: <www.record.com.br/autor_entrevista.asp?id_autor=31\&id_ entrevista=22>. Acesso em: 16 ago. 2013.

PEREIRA, Antônio Marcos. Romance-ensaio: três casos. Texto apresentado no XII Congresso Internacional da Abralic, 18, Curitiba, 2011. (Mimeo)

POZUELO, José María. Figuraciones del yo en la narrativa: Javier Marías y E. Vila-Matas. Valladolid: Junta de Castilla y León; Universidad de Valladolid, 2010.

SEARLE, John Rogers. Actos de habla. Ensayo de filosofia del lenguaje. Madrid: Planeta Agostini, 1994.

STIERLE, Karlheinz. A fiç̧ão. Trad. Luiz Costa-Lima. Rio de Janeiro: Novos Cadernos do Mestrado/Letras, UERJ, 2006.

TODOROV, Tzvetan. Critique de la critique. Un roman d'apprentissage. Paris: Éditions du Seuil, 1984 . 
Remate de Males, Campinas-SP, v. 37, n. 2, p. 581-595, jul./dez. 2017 - 595

VILA-MATAS, Enrique. Bartleby y compañía. Barcelona: Anagrama, 2000.

VILA-MATAS, Enrique. Qué Pasa, Santiago de Chile, 15/o7/2001, p. 13.

WATT, Ian. A ascensão do romance. São Paulo: Companhia das letras, 2010. 